\title{
The Development of Physical Aggression from Toddlerhood to Pre-Adolescence: A Nation Wide Longitudinal Study of Canadian Children
}

\author{
Sylvana M. Côté, ${ }^{1,6}$ Tracy Vaillancourt, ${ }^{2}$ John C. LeBlanc, ${ }^{3}$ \\ Daniel S. Nagin, ${ }^{4}$ and Richard E. Tremblay ${ }^{5}$
}

Received April 22, 2004; revision received January 18, 2005; accepted March 21, 2005

Published online: 25 March 2006

The objectives of the study were to model the developmental trajectories of physical aggression (PA) from toddlerhood to pre-adolescence and to identify risk factors that distinguish typical (normative) from atypical developmental patterns. Ten cohorts of approximately 1,000 children $(n=10,658)$ drawn form a nationally representative (Canadian) sample were followed over 6 years. Using a group-based trajectory approach, we identified three groups of children with distinct developmental trajectories between 2 and 11 years of age. One third of the children (31.1\%) followed a low desisting trajectory, reflected in infrequent use of PA in toddlerhood and virtually no PA by pre-adolescence. The majority of children $(52.2 \%)$ followed a moderate desisting trajectory, reflected in occasional use of PA in toddlerhood and infrequent use by pre-adolescence. One sixth of the children (16.6\%) followed a high stable trajectory of PA. Multivariate logistic regression indicated that children in the high PA trajectory group were more likely to be boys (OR: 1.67; CI: 1.5-1.87), from low income families (OR: 1.4; CI; 1.27-1.67), from families where the mother had not completed high school (OR: 1.20; CI: 1.05-1.38) and who reported using hostile/ineffective parenting strategies (OR: 1.16; CI: 1.14-1.18). In sum, the results indicate that the typical developmental pattern of PA was one of occasional and declining use over time. However, about one sixth of children, mostly boys from disadvantaged families, exhibited an atypical developmental pattern reflected in more frequent and stable use of PA. The results suggest that most children learned relatively well to inhibit PA by the end of childhood and that a minority failed to do so. Family risks traditionally found to be associated with antisocial behaviors during adolescence appear to interfere with the socialization of PA during early and middle childhood.

KEY WORDS: developmental trajectories; physical aggression; toddlerhood; middle childhood; family risk factors.

${ }^{1}$ School of Psychoéducation, University of Montréal, Montreal, Quebec, Canada.

2 Department of Psychology, McMaster University, Hamilton, Ontario, Canada.

${ }^{3}$ Department of Pediatrics and Psychiatry, Dalhousie University, Halifax, Nova Scotia, Canada.

${ }^{4}$ H. J. Heinz III School of Public Policy and Management, Carnegie Mellon University, Pittsburgh, Pennsylvania.

${ }^{5}$ Canada Research Chair, University of Montréal, Montréal, Québec, Canada.

${ }^{6}$ Address all correspondence to Sylvana M. Côté, University of Montréal, 90 ave. Vincent-d'Indy, C.P. 6128 Succursale centre-ville, Montréal, H3C 3J7, Canada; e-mail: sylvana.cote@umontreal.ca.

\section{INTRODUCTION}

Although aggressive behaviors may be adaptive and necessary for survival (Archer \& Côté, 2005; Cairns, 1979; Darwin, 1872; Lorenz, 1966), atypically high levels of aggression, especially physical aggression, are generally associated with a wide range of social problems (Krug, Dahlberg, Mercy, Zwi, \& Lozano, 2002; McCord, Spatz Widom, \& Crowell, 2001). Studies have shown that such problematic levels of aggression in adolescence or adulthood can be identified in the preschool years (Keenan \& Wakschlag, 2000) and can be traced to events occurring 
early in life (Arseneault et al., 2003; Caspi et al., 2002; Moffitt, Caspi, Rutter, \& Silva, 2001; Nagin \& Tremblay, 2001). However, no studies have mapped the development of PA between toddlerhood and adolescence or adulthood. Therefore, the extent to which aggression in early childhood represents a risk for continued aggression is unclear.

Research on the development of aggression needs to reconcile three apparently contradictory findings: (1) most preschoolers use physical aggression; (2) the earlier the onset of problem behaviors, the higher the risk for continued aggression and violence, yet, (3) only a small proportion of individuals are persistently physically aggressive (Brame, Nagin, \& Tremblay, 2001; Broidy et al., 2003). One challenge is to distinguish between the normative patterns of aggressive behaviors and the more atypical pattern that may represent a risk for future difficulties. The distinction is important for the identification of children at risk and for the implementation of preventive interventions.

The present study maps the developmental course of physical aggression (PA) from toddlerhood to preadolescence with the aim of: (1) distinguishing between typical (or normative) and atypically high developmental trajectories of PA and (2) identifying risk factors associated with high PA trajectories. The term physical aggression is used to refer to physical acts that are directed at another person and that can potentially be harmful (e.g., kicking, pushing, hitting; Cairns, Cairns, Neckerman, Ferguson, \& Gariepy, 1989; Straus \& Gelles, 1990; Tremblay, 2000).

\section{Normative Developmental Patterns of Aggressive Behaviors}

Different views on the normative development of aggression have been proposed. For instance, the social learning perspective posits that children learn to aggress during the course of childhood and adolescence (Bandura, 1973; Loeber \& Stouthamer-Loeber, 1998; Reiss \& Roth, 1993) and that social influences, such as violent television or deviant peers, generally promote the expression of physical aggression (Johnson, Cohen, Smailes, Kasen, \& Brook, 2002; Thornberry, 1998). Within this view, children are typically expected to exhibit more PA as they approach adolescence.

A different view posits that children learn to exert control over their emotions and their behaviors, and that they generally become more able to respect social norms as they age (Cairns, 1979; Goodenough, 1931; Tremblay, 2003; Tremblay \& Nagin, 2005). Within this view, children are typically expected to exhibit less PA as they approach adolescence.
Studies investigating the development of aggression have reported increasing as well as decreasing levels of aggressive behaviors during the course of childhood. The specific developmental pattern appears to depend on two main sources of variation. The first is the type of aggressive behavior studied. For instance, levels of indirect or relational aggression (e.g., rumor spreading and peer group exclusion) appear to increase during the elementary school years (Côté, Vaillancourt, Barker, Nagin, \& Tremblay, in press; Crick, Ostrov, Appleyard, Jansen, \& Casas, 2004; Tremblay et al., 1996; Vaillancourt, 2005), while levels of physical aggression appear to decrease (Broidy et al. 2003; Cairns et al., 1989; Côté et al., in press; Nagin \& Tremblay, 1999). The second is the developmental period that is studied. For instance, levels of physical aggression were shown to increase during the preschool years (Tremblay et al., 2004) and to decrease from the preschool years to adolescence (Broidy et al., 2003; Nagin \& Tremblay, 1999; NICHD Early Child Care Research Network, 2004).

\section{Atypical Developmental Patterns}

Recent longitudinal studies on the development of PA (Brame et al., 2001; Broidy et al., 2003; Nagin \& Tremblay, 1999; NICHD ECCRN, 2004; Tremblay et al., 2004) have shown that there is heterogeneity in the development of aggression. That is, not all children follow the same developmental trajectories. For instance, although the majority of children follow declining trajectories of PA between kindergarten and grade 6 , a minority of kindergarten children follow high and mostly stable trajectories (Broidy et al., 2003; Nagin \& Tremblay, 1999). Furthermore, these kindergarten children are at risk for different forms of delinquency, including violence in adolescence (Broidy et al., 2003; Brame et al., 2001).

To date, we know little about the developmental patterns preceding high levels of physical aggression in kindergarten. There is evidence suggesting that some children begin to use physical aggression in kindergarten as a result of the stress generated by the transition from preschool to formal schooling. For example, Kingston and Prior (1995) identified a group of children who exhibited substantial increase in aggressive behaviors at the beginning of formal schooling. This group of children was mainly characterized by their poor adaptive functioning in school, suggesting that the stress related to school entry could have fostered the use of aggression (Kingston $\&$ Prior, 1995). Further support for this hypothesis comes from results indicating that low academic competence and problem behaviors influence each other at the beginning of formal schooling (Welsh, Parke, Widaman, \& O'Neil, 
2001). Thus, highly physically aggressive kindergarten children may be those who are using aggression as a way of coping with a particularly stressful transition-entry into the formal school system.

Another explanation for the high levels of physical aggression at school entry is that aggressive kindergarten children follow trajectories that started much earlier (Hay, Castle, \& Davies, 2000; Keenan \& Wakschlag, 2000). The few studies that have focused on physically aggressive behaviors during infancy and toddlerhood show that occasional use of aggression is common among preschool children (Dionne, Tremblay, Boivin, Laplante, \& Pérusse, 2003; Goodenough, 1931; Tremblay et al., 1999; Tremblay et al., 2004). Moreover, two recent studies on the development of PA or conduct problems from toddlerhood to middle childhood support the possibility that aggression in kindergarten reflects the continuation of a behavior pattern that began in the preschool years.

First, the NICHD ECCRN (2004) distinguished among five groups of children with distinct trajectories of PA between the 2 years of age and the third grade. The sample included 1,100 children and their mother recruited at 10 selected sites in the US. Fifteen percent of the children exhibited moderate levels of PA while 3\% exhibited high levels. Second, Shaw, Gilliom, Ingoldsby, and Nagin (2003) distinguished among four groups of boys with distinct levels of conduct problems between the ages of 2 and 8 years among their sample of low income boys $(n=284)$. Six percent of those boys already exhibited elevated levels in toddlerhood and maintained high levels in middle childhood (Shaw et al., 2003). Thus, some preschoolers may already present levels of aggression that represent a risk for future problems, and the elevated levels of aggression observed in school age children might be the continuation of a pattern that started in toddlerhood.

Together these studies suggest the existence of two different developmental pathways of PA: one that begins before school entry and one that begins at school entry. These pathways are not necessarily mutually exclusive. Some children may follow rising trajectories, while others may follow declining trajectories. In fact, aggression during the preschool years is characterized by substantial variability in its frequency and stability (Dionne et al., 2003; Keenan \& Shaw, 1994; Munson, McMahon, \& Spieker, 2001). Thus, groups of children with distinct (and potentially opposite) developmental trajectories of PA could be identified.

Note that the studies mentioned above either examined the development of PA among preschool children (Tremblay et al., 2004), or among elementary school age children (Broidy et al., 2003; Nagin \& Tremblay, 1999), using at risk samples (e.g., low socioeconomic status boys;
Nagin \& Tremblay, 1999; Shaw et al., 2003), samples representative of specific areas (NICHD ECCRN, 2004), small samples (e.g., Hay et al., 2000) or clinically referred children (Keenan \& Wakschlag, 2000). To our knowledge, no study has provided information on the developmental trajectories of PA from toddlerhood to pre-adolescence using a nationally representative sample that includes both girls and boys. This was one aim of the present study.

\section{Factors Associated with Atypical Developmental Patterns of Physical Aggression}

One implicit assumption about the identification of heterogeneity in a population is that the groups exhibiting atypical development have specific risk characteristics. For instance, Nagin and Tremblay (2001) found that chronically physically aggressive boys (between the ages of 6 and 15 years) from low socioeconomic areas were more likely to have mothers who started childbearing early and who had low levels of education than the boys with low or decreasing use of PA. Similar predictors (i.e., early child bearing, low SES) were found to predict the highest PA trajectory in the preschool years (Tremblay et al., 2004). The NICHD ECCRN (2004) study found that higher levels of socio demographic risk (e.g., poverty, low maternal education, single parenting), as well as less sensitive and involved parenting during the course of childhood were associated with higher and more stable trajectories of PA. Finally, in the Shaw et al. (2003) study, boys who exhibited persistent conduct problems were more fearless and more likely to have experienced maternal rejection. These results suggest that similar risk factors are predictive of children's stable tendencies to manifest conduct problems (more generally) or physical aggression (specifically), whether they are measured during the preschool period or at the beginning of schooling.

One aim of the present study is to examine, among a large $(n=10,658)$ nationally representative sample of boys and girls, the extent to which family risk factors can distinguish between typical and atypical trajectories of PA that begin in toddlerhood and continue during middle childhood for boys and girls. Specifically, we predicted trajectories of PA from family characteristics (i.e., early motherhood, age and education of the mother, low family income and family status), as well as family process variables such as family functioning, and parenting practices. According to some developmental models, such family risk environments may lead to coercive family interactions and promote the use of aggression among 
children (e.g., Patterson, 1982; Patterson, Reid, \& Dishion, 1992).

\section{Sex Differences in the Development of Physical Aggression}

The limited amount of information concerning the comparative development of boys and girls' aggressive behaviors during the early years is a notable gap in the literature. Hence, the preschool period may be particularly important for differentiating the problem behaviors of boys and girls, and information about this differentiation may shed light on the etiology of conduct problems.

Specifically, it has been suggested that the emergence of sex differences in externalizing behaviors (which comprise PA) occurs during the preschool years (Keenan \& Shaw, 1997). Studies have clearly demonstrated that boys are more physically aggressive than girls after school entry (Broidy et al., 2003; Cairns et al., 1989; Tremblay et al., 1996). However, it is not clear whether boys are more aggressive during the preschool years. For instance, some reported no sex differences in externalizing behaviors (Hay et al., 2000) or in conduct problems (Keenan \& Wakschlag, 2000) among preschoolers, while others reported boys (NICHD ECCRN, 2004; Tremblay et al., 1996; Tremblay et al., 2004), and still others girls (Munson et al., 2001) to be the more aggressive sex. Many of these studies used small and/or clinical samples. Thus, there is a need for studies examining the extent to which boys and girls follow different trajectories of PA during childhood in large population samples.

\section{Study Objectives}

In the present study, we modeled the developmental trajectories (Boulerice, 2001; Nagin, 1999; Nagin, 2005) of PA among a nationally representative sample of Canadian children between 2 and 11 years of age in order to answer five questions: (1) what are the typical (normative) developmental trajectories of PA between 2 and 11 years of age? (2) is there a group of children who follow atypically elevated trajectories of PA throughout that age period? (3) is there a group of children who are not physically aggressive during toddlerhood but become physically aggressive as they enter school? (4) do sex differences become gradually larger between 2 and 11 years of age? and (5) what risk factors distinguish children who follow an atypically high PA trajectories from those who do not?

\section{METHOD}

\section{Sample}

The National Longitudinal Survey of Children and Youth (NLSCY) sample is a probability sample constructed while taking two important requirements into consideration. First, a sufficient sample was required in each of the 10 Canadian provinces to allow for the production of reliable estimates for all children 0 to 11 years of age. The sample allocation was derived in such a manner that smaller provinces had a sufficient sample to meet this requirement. A second requirement was to have a large enough sample to produce estimates at the Country level by seven key age groups (0-11 months; 1,2 to 3,4 to 5 , 6 to 7,8 to 9 and 10 to 11 years) (NLSCY 1994-1995).

All analyses conducted on the NLSCY are weighted. The principle behind estimation in a probability sample such as the NLSCY is that each person in the sample represents, besides himself or herself, several other persons not included in the sample. For example, in a $2 \%$ simple random sample of the population, each person in the sample represents 50 persons in the population. The weighting phase is a step which calculates, for each record, the number of individual in the population represented by a given record. In longitudinal analyses as those done in the present study, the modeling of the trajectories included probability weights that appropriately reflected the sampling strategy of this probability survey and accounted for non-response, attrition, rural-urban factor, inter-provincial migration, and post-stratification (NLSCY 1994-1995).

In 1994, a random sample of 15,579 Canadian households with at least one child aged 0 to 11 years was selected by Statistics Canada for a longitudinal study of children's development (Human Resources Development Canada, 1996). Response was obtained for 13,439 of these selected households-an overall response rate of $86.3 \%$.

Data collection was undertaken every 2 years through home interviews with the person most knowledgeable about the child (PMK). Data from cycle 1 (1994-1995), cycle 2 (1996-1997), cycle 3 (1998-1999), and cycle 4 (2000-2001) were available for analysis at the time of the present study. Other details about the study can be found in Statistics Canada and Human Resources Development Canada (1995).

From the 13,439 households with children under 11 years of age at cycle 1 , we selected children aged between birth and 9 years at cycle 1 who were followed longitudinally and who had at least two PA assessments $(n=10,658)$. Only 127 children had more than two missing PA assessments and their PA scores were not 
Table I. Characteristics of the Sample at Cycle $1(n=10,658$ Unless Otherwise Indicated $)^{a}$

\begin{tabular}{|c|c|c|}
\hline & $n$ & $\%$ \\
\hline \multicolumn{3}{|l|}{ Sex of child } \\
\hline Male & 5,459 & 51.22 \\
\hline Female & 5,199 & 48.78 \\
\hline \multicolumn{3}{|c|}{$\begin{array}{l}\text { Age group of mother at birth of first child } \\
(n=9,420)\end{array}$} \\
\hline 21 years or less & 2,302 & 24.45 \\
\hline Older than 21 years & 7,115 & 75.55 \\
\hline \multicolumn{3}{|c|}{$\begin{array}{l}\text { Mother graduated from high school } \\
\quad(n=10,621)\end{array}$} \\
\hline Yes & 8,353 & 78.65 \\
\hline No & 2,268 & 21.35 \\
\hline \multicolumn{3}{|c|}{$\begin{array}{l}\text { Father graduated from high school } \\
\qquad(n=8,873)\end{array}$} \\
\hline Yes & 6,794 & 76.57 \\
\hline No & 2,079 & 23.43 \\
\hline \multicolumn{3}{|c|}{$\begin{array}{l}\text { Mother employed outside the home } \\
\quad(n=7,179)\end{array}$} \\
\hline Yes & 5,815 & 81.01 \\
\hline No & 1,363 & 18.99 \\
\hline \multicolumn{3}{|c|}{$\begin{array}{l}\text { Father employed outside the home } \\
\qquad(n=8,388)\end{array}$} \\
\hline Yes & 7,507 & 89.51 \\
\hline No & 879 & 10.49 \\
\hline \multicolumn{3}{|c|}{ Family status at time of interview } \\
\hline Two parents & 8,194 & 76.88 \\
\hline One parent & 2,464 & 23.12 \\
\hline \multicolumn{3}{|c|}{ Number of siblings in the home } \\
\hline None & 2,226 & 20.88 \\
\hline One or more & 8,432 & 79.12 \\
\hline \multicolumn{3}{|l|}{ Family income (in 1994) } \\
\hline Less than $25,000 \$$ & 2,412 & 22.63 \\
\hline $25,000 \$-40,000 \$$ & 2,489 & 23.36 \\
\hline $41,000 \$-60,000 \$$ & 3,067 & 28.77 \\
\hline More than $60,000 \$$ & 2,690 & 25.24 \\
\hline
\end{tabular}

${ }^{a}$ The number of participants is weighted and rounded.

significantly different from those children who were included in the analyses (at cycle 1: mean PA excluded $=$ 1.04 vs. included $=1.12 ; p=0.68$; at cycle 2 : mean PA excluded $=0.98$ vs. included $=1.02, p=0.83$ ). Table I presents the characteristics of the sample.

The study uses a longitudinal accelerated design. This implies that overlapping trajectories of a maximum length of 6 years were combined into summary trajectories that began at age 2 and ended at age 11 years. Specifically, we used data collected on children from 10 different age groups, or cohorts, who were followed for a shorter interval (6 years) than the age range for which data were available (ages 2 to 11: 9 years).

The design of the study has some implications for the modeling of trajectories. For example, data from cohort 3 served to estimate trajectory points at the ages of 2 ,
4,6 , and 8 years, while data from cohort 4 served to estimate the trajectory points at ages $3,5,7$, and 9 years. Thus, the children contributing a data point at age 2 were from a different cohort than those contributing for age 3 , although only one year separated their birth. We tested for the possibility of cohort effects (see analyses section).

\section{Instruments and Procedures}

Trained interviewers visited the participants in their homes. We used data from a face-to-face interview with the Person Most Knowledgeable about the child (PMK), which was the biological or adoptive mother in $91.4 \%$ of interviews. In the remaining cases, the PMK was the biological father $(6.6 \%)$, another family member (e.g., grand-mother: $1.3 \%)$, or a step-parent $(0.6 \%)$. Informed consent was obtained from all PMKs.

\section{Assessment of PA During Childhood}

The frequency of PA was assessed between the ages of 2 and 11 years in the NLSCY sample. The PMK rated the frequency at which the child was physically aggressive along a three-point scale ranging from "Never" (0) to "Sometimes" (1) to "Often" (2). The physical aggression items were: "kicks, bites, hits other children"; "gets into many fights"; and "reacts with anger and fighting." The items were summed into a physical aggression scale that had a minimum of 0 and a maximum of 6 . A score of 2 on the scale reflects the fact that children "sometimes" or occasionally exhibit some of the physically aggressive behaviors or alternatively, frequently use one physically aggressive behavior. The reliability coefficients for the scale ranged between 0.60 and 0.76 and tended to be higher among older children. These coefficients are comparable to those obtained in previous studies in Canada, New Zealand, and the United States which used a similar PA scale among school age children (Broidy et al., 2003). The scale was shown to have good predictive value for adolescent violent behaviors (Broidy et al., 2003; Nagin \& Tremblay, 1999).

\section{Predictors of the High PA Trajectory}

\section{Family Characteristics}

We selected cycle 1 family and child variables that were conceptually or empirically related to the development of aggressive behaviors (e.g., Jaffee, Caspi, 
Moffitt, Belsky, \& Silva, 2001; Nagin \& Tremblay, 2001; Tremblay, 2000; Tremblay et al., 2004). The predictors were dichotomized and coded to represent risk. First, early childbearing was coded according to whether the mother was 21 years or less at the birth of the first child (1) or more than 21 years (0). Being younger than 21 years old at the time of the birth of the first child was shown to be a valid indicator of risk in several Canadian studies (e.g., Tremblay et al., 2004; Nagin \& Tremblay, 2001). Third, low maternal education was coded according to whether the mother had a high-school diploma (0) or not (1). Fourth, single-parent family was coded according to whether both parents were living with the child $(0)$ or not (1). Fifth, low household income was coded according to whether the family income was at or below the 25th percentile of the income distribution (1) or above the 25th percentile (0). Not having graduated from high school, single parent families, and low income have been commonly used as indicators of risk and have been shown to predict children's maladjustment (e.g., NICHD ECCRN, 2004, Tremblay et al., 2004; Nagin \& Tremblay, 2001). We selected predictors that were related to the mother or to the family and not to the father specifically because of missing values on variables concerning the father.

\section{Family Processes Variables}

Three parenting scales were used to predict membership in the trajectory groups: Positive parenting, hostile/inefficient parenting, and consistent parenting. Mothers rated the frequency of specific parenting behaviors on a scales ranging from "never" to "many times each day." The positive parenting scale included four items reflecting the frequency with which the parent plays, laughs, or does enjoyable things with his/her child. Scores ranged between 0 and 20. High scores indicated more positive interactions. The Cronbach $\alpha$ was 0.81 . The hostile/ineffective scale included seven items reflecting the frequency with which the parent becomes annoyed with the child, praises the child (scored negatively); disapproves of the child's behavior; gets angry and punishes the child; or feels ineffective at managing the child. Scores ranged between 0 and 25. High scores indicated more hostile/ineffective interactions. The Cronbach $\alpha$ was 0.71 . The consistent parenting scale includes five items reflecting the frequency at which the parent makes sure that the child does what he/she was asked to do, or the frequency with which the child gets away with things for which he/she should have been punished. Scores ranged between 0 and 20. A high score indicates consistent parenting. The Cronbach $\alpha$ was 0.66 . Finally, we used a scale composed of 12 items measuring the quality of family functioning (communication, problem resolution, control of disruptive behavior, showing and receiving affection; Boyle et al., 1987). The scores ranged from 0 to 36 on the scale. The Cronbach $\alpha$ was 0.88 . Thus, the predictors, taken from the home interview conducted at cycle 1 were household income; mother's age at birth of first child; mother's level of education; family composition, parenting practices and family functioning.

\section{Analyses}

\section{Trajectory Model Estimation}

Main Model. We first estimated trajectory group models in order to identify groups of children with distinct developmental patterns. Toward this end, a semi-parametric group-based approach (Jones, Nagin, \& Roeder, 2001; Nagin, 1999, 2005) was used to examine the development of PA over time. Specifically, a general nonlinear Mixtures of Curves program (MOC) (Boulerice, 2001) served to identify subgroups of children with distinct developmental trajectories of physical aggression across the four assessments. The trajectory methodology uses all available developmental data points and assigns individuals to categories on the basis of a posterior probability rule. Resulting groups are meant to represent approximations of an underlying continuous process (Nagin, 2005; Nagin \& Tremblay, 1999, 2001).

First, in order to identify the model with the preferred number of groups, models with a varying number of trajectories were estimated. Second, for each group in the preferred model, parameters for constant (i.e., intercept), linear, quadratic and cubic terms were estimated. We modeled the data according to a zero-inflated Poisson distribution.

Selection of the best fitting model was determined using the Bayesian Information Criterion (BIC), as well as other fit indices such as the examination of the entropy and comparison of fitted versus observed values. The BIC was calculated as: $\mathrm{BIC}=-2 \log (L)+\log (n) \times k$, where $L$ is the model's maximized likelihood, $n$ is the sample size, and $k$ is the number of parameters in the model. The entropy is an index indicating the extent to which the groups are well separated. It also reflects the extent to which subjects can be classified with confidence in a given trajectory group. For instance, if two trajectory groups have similar intercept and slope, the entropy will be poor (groups are not well separated) and the probabilities that a subject is classified in one of the two groups will be low (poor prediction of group membership). The model which minimized the BIC (Schwarz, 1978) and maximized the entropy was chosen. 
The statistical procedure yields, for every subject, the probability of being classified in each of the trajectory groups. The "posterior probabilities of group membership" were central to the analysis. For each individual in the sample, the posterior probabilities estimate the probability of the child belonging to each trajectory group. For example, consider a child whose mother persistently rated him as highly physically aggressive. For this individual the posterior probability estimate of the child belonging to a low trajectory group would be near zero, whereas the probability estimate of the child belonging to a high aggression group would be large. Each child was assigned to the group for which he or she had the largest posterior probability estimate. This is the group that best conforms to the child's observed behavior. Ideally, the posterior probability should be near 1 for this trajectory group. In the present analysis, the average posterior probability for the assigned group ranged between 0.77 and 0.79 , thereby indicating good fit of the model (Nagin, 1999, 2005).

In subsequent analyses involving prediction of the high trajectory group membership, the posterior probabilities are used for weighting of the data and therefore allow for correction of the assignment rule.

Tests of Cohort Effects. We tested for the presence of cohort effects that could threaten the validity of estimating trajectories with children of different ages at cycle 1 . Thus, the analysis aimed at testing whether there was an effect of age on the trajectories. Specifically, a multinomial logit model was estimated with the trajectories of PA as the outcome and age at cycle 1 as the independent variable. Recall that the age of the participants varied between 0 and 9 years at cycle 1, each age group of one year representing one cohort. Therefore, the cohort variable was dummy coded (varying between 0 and 9) and entered in the regression. The reference group was the last cohort. The overall chi-square for the cohort variable was 15.92 and was not statistically significant $(p=0.07)$, rejecting the hypothesis that age at cycle 1 had an effect on the trajectories.

In order to test for the possibility that age was associated with PA for one sex but not the other, we conducted an additional analysis. Specifically, the interaction between cohort and sex was entered in a multinomial logit model. The sex X cohort variable was not statistically significant $\left(\chi^{2}=2.31, p=0.99\right)$, indicating that there was no variation in the association between age and PA by sex.

\section{Predictors of the High PA Trajectory}

Multivariate logit regression was then used to examine the capacity of the family risk factors to distinguish membership in the highest physical aggression trajectory group controlling for the levels of the other risk factors. Two models were tested. In the first, the sex of the child and family characteristics (early motherhood, low maternal education, separated family, low income) were entered as predictors of the high-level trajectory of PA. In the second, sex, family characteristics, and family processes (positive, hostile, and consistent parenting; family functioning) variables were entered. In addition, we tested all interactions between the predictors and the sex of the child in order to examine potential sex differences in the predictors.

\section{Results}

Table II presents the means and standard deviations on PA scores by cohort, sex and age. As Table II indicates, the mean physical aggression scores generally declined with age and are lower for girls. We then estimated group-based developmental trajectory models. The best fitting model included three trajectory groups and is presented in Fig. 1. The bold lines represent trajectories of actual behaviors, calculated as the children's mean scores weighted by the probability of belonging to the trajectory to which they were assigned. The light lines represent predicted behaviors and are calculated using the model's coefficient estimates.

The procedure identified a "low desister" group to which $31.1 \%$ of the sample was estimated to belong. These children exhibited low frequencies of PA in toddlerhood and declining levels during the preschool and elementary school years. They exhibited virtually no PA by age 11 years. The second group was labeled "moderate desister" and represented $52.2 \%$ of the sample. The moderate desisters exhibited moderate (or occasional) use of PA in toddlerhood and declining levels during the preschool and elementary school years. They exhibited PA infrequently by age 11 years. Finally, the third group was labeled "high stable" and represented $16.6 \%$ of the sample. Children in this group exhibited more frequent use of PA in toddlerhood as compared to their peers, and their levels remained high and stable during the preschool and elementary school years. The proportions of boys in the low desister, moderate desister and high trajectories were $43.86,52.25$, and $61.76 \%$, respectively.

\section{Physical Aggression Trajectories by Sex}

With the intention of comparing the development of boys and girls, we first estimated separate models for each 


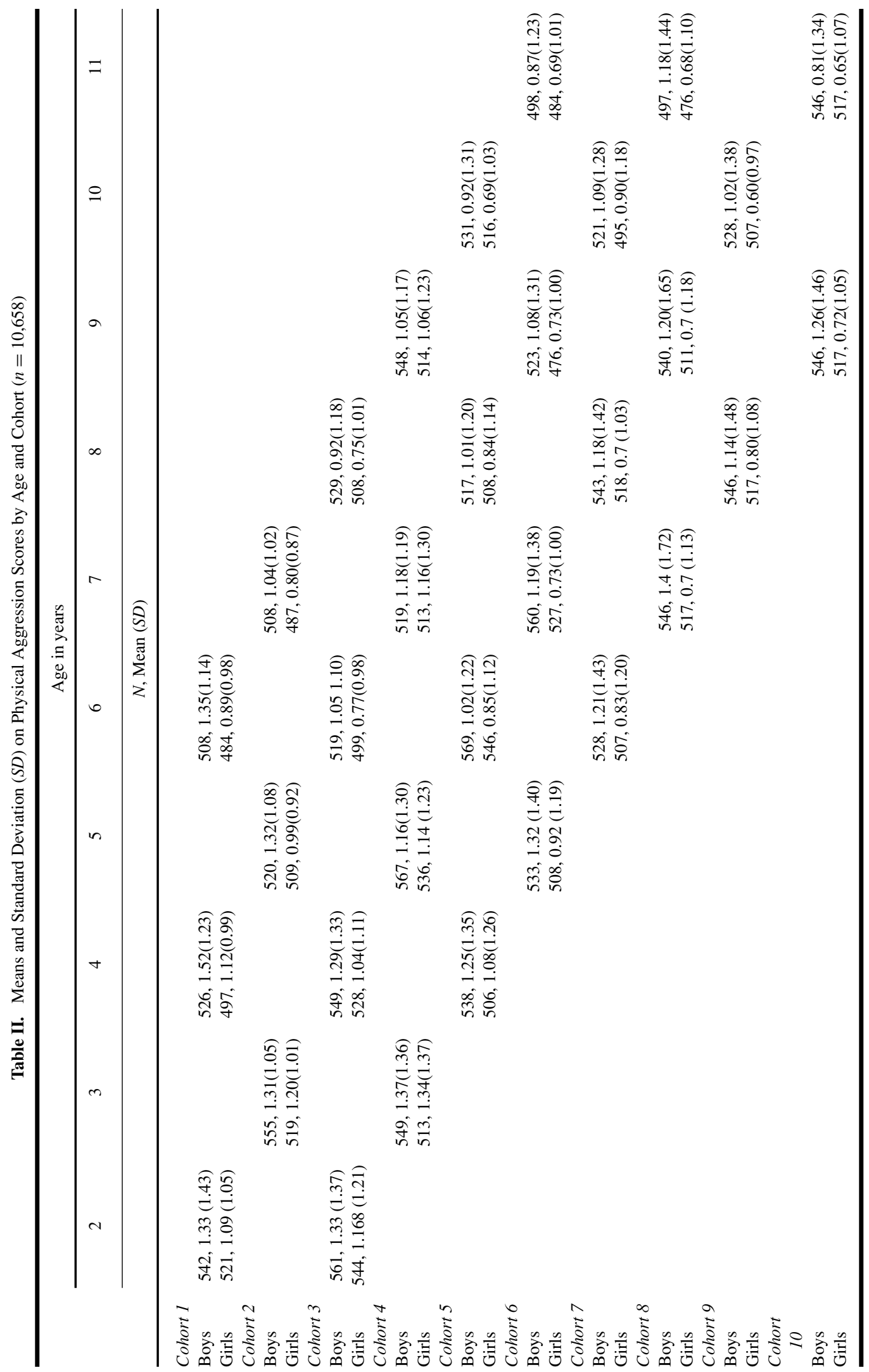




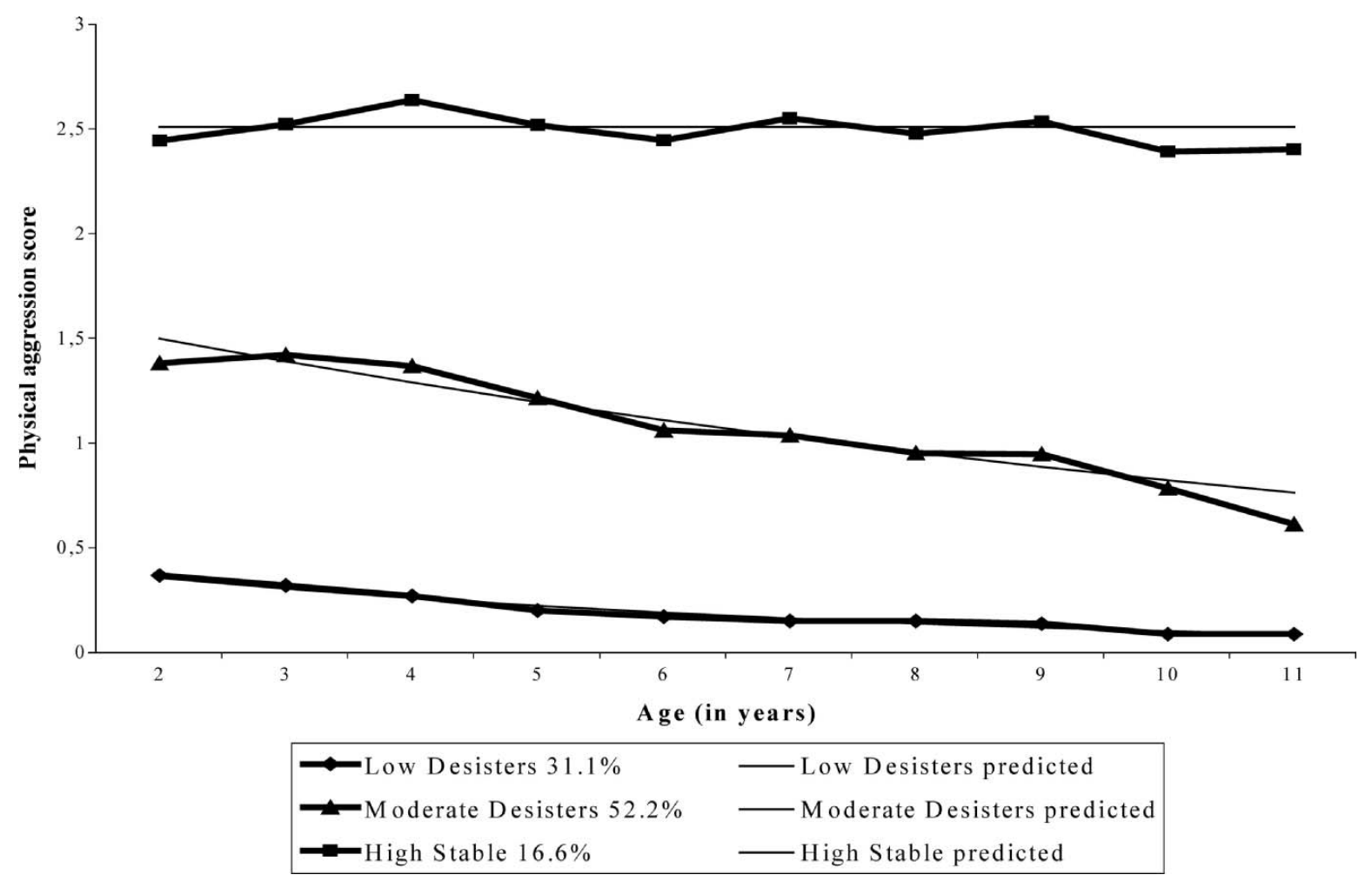

Fig. 1. Trajectories of physical aggression from 2 to 11 years $(n=10,658)$.

sex. The trajectory model for boys had the same number $(n=3)$ of trajectory groups and similar trajectory shapes as the trajectory model for girls. The differences between the two models were mainly related to differences in the proportions of children in each trajectory group. For instance, there were approximately twice as many boys than girls in the highest trajectory identified in the within sex models. Given the similarities in the developmental patterns, we chose to examine sex differences by comparing the proportions of boys and girls in a trajectory model estimated for both sexes. The sex of the child was used as a risk factor in the prediction analyses described below.

\section{Predictors of the High PA Trajectory}

Table III presents the correlations among the demographic measures and among the family functioning and parenting measures. ANOVA's were conducted to examine whether higher and lower risk status were associated differentially with parenting and family functioning.

Table IV reports the prevalence of each risk factor by trajectory group. Note that the prevalence levels generally increase from the low- to the medium- to the highaggression trajectory groups. For all predictors, the high group has the highest prevalence of family risk characteristics, the highest scores on hostile parenting and family functioning (higher score indicating more dysfunction), and the lowest scores on positive and consistent parenting.

Table $\mathrm{V}$ reports the results of the logistic regression analysis aimed at identifying risk factors distinguishing the high aggression trajectory group in the context of a multivariate model. In the first model, only the sex of the child and family characteristics were entered. The results indicated that the largest risk for a high PA trajectory was being a male (OR: 1.67). The next two largest risks were a low family income (OR: 1.45) and low maternal education (OR: 1.20 ). In the second model, we added the family processes variables. The results indicate that the significant effects of sex, income and maternal education remained significant. In addition, we found hostile/ineffective parenting to be a strong predictor of membership in the high PA trajectory. None of the interactions between sex and the predictors were significant.

\section{DISCUSSION}

This study is the first to report on the development of physical aggression among a large nationally 
Table III. Bivariate Associations (Correlations or Anovas) Among Predictor Variables (See Note Below)

\begin{tabular}{|c|c|c|c|c|c|c|c|c|}
\hline & 1 & 2 & 3 & 4 & 5 & 6 & 7 & 8 \\
\hline 1. Sex of Child & - & & & & & & & \\
\hline 2. Early motherhood & -.013 & - & & & & & & \\
\hline 3. Low income & 0.00 & $0.31^{*}$ & - & & & & & \\
\hline 4. Low education & $0.04^{* *}$ & $0.28^{* *}$ & $0.31^{* *}$ & - & & & & \\
\hline 5. Separated family & 0.00 & $0.28^{* *}$ & $0.39^{* *}$ & $0.23^{* *}$ & - & & & \\
\hline 6. Positive parenting & 2.10 & $6.52^{*}$ & $13.71^{* *}$ & $8.05 *$ & 1.51 & - & & \\
\hline 7. Hostile/ineffective parenting & $55.58^{* *}$ & 0.21 & $14.17^{* *}$ & $14.91^{* *}$ & $7.6^{* *}$ & $-0.19^{* *}$ & - & \\
\hline 8. Consistency in parenting & 0.99 & $45.94^{* *}$ & $54.29^{* *}$ & $205.1^{* *}$ & $14.37^{* *}$ & $0.07^{* *}$ & $-0.27^{* *}$ & - \\
\hline 9. Family functioning & 4.13 & $93.24^{* *}$ & $94.55^{* *}$ & $171.08^{* *}$ & $100.03^{* *}$ & $-0.21^{* *}$ & $0.21^{* *}$ & $-0.21^{* *}$ \\
\hline
\end{tabular}

Note. ANOVAS were conducted to measure the associations between the categorical and continuous predictors. F values are presented. ${ }^{*} p<.05{ }^{* *} p<.001$.

representative sample, with data on both sexes, from two to 11 years of age. Using a group-based trajectory methodology, we modeled the development of PA among more than 10,000 children assessed four times over 6 years. We found that occasional use of physical aggression was frequent among preschool children, and that a minority used PA more frequently. Toddlers with occasional or infrequent use of PA followed declining trajectories, while those who used it frequently were at risk of remaining on a high-level trajectory throughout childhood. Children in the high PA trajectory group were more likely to be boys, from low income families, with mothers who had not completed high school and who reported using hostile/ineffective parenting strategies. These results from a representative Canadian sample of children are in line with a recent large US study (NICHD ECCRN, 2004) covering a similar age range and showing that physical aggression tends to be more stable in the context of family adversity.
The present study addressed five important questions concerning the development of physical aggression. First, we found that at the earliest assessment, in toddlerhood, PA was part of most children's behavioral repertoire, but that the typical developmental trajectory was one of declining frequency of use. Specifically, the moderate-desister group represented $52.2 \%$ of children with occasional use of PA in toddlerhood who desisted to infrequent use by 11 years. The low-level desister group represented $31.1 \%$ of children who exhibited infrequent use in toddlerhood and virtually no PA by 11 years. The overall pattern of results for the shape of the development trajectories is similar to that found in the NICHD ECCRN (2004) study, where most children were also found to exhibit low to moderate levels of PA and to be following declining trajectories between toddlerhood and middle childhood. One difference between the NICHD ECCRN trajectory results and the present results is the number of groups identified.

Table IV. Child and Family Characteristics by Physical Aggression Trajectory Group

\begin{tabular}{|c|c|c|c|c|c|c|}
\hline \multirow[b]{2}{*}{ Boys } & \multicolumn{2}{|c|}{$\begin{array}{c}\text { Group 1: Low } \\
(n=3,315) \\
\%\end{array}$} & \multicolumn{2}{|c|}{$\begin{array}{c}\text { Group 2: Desister } \\
(n=5,563) \\
\%\end{array}$} & \multicolumn{2}{|c|}{$\begin{array}{c}\text { Group 3: High } \\
\text { stable }(n=1,769) \\
\%\end{array}$} \\
\hline & 43.86 & & 52.25 & & 61.75 & \\
\hline \multicolumn{7}{|l|}{ Family characteristics } \\
\hline Low income & 22.94 & & 24.29 & & 32.66 & \\
\hline Early motherhood $^{a}$ & 21.97 & & 24.69 & & 28.17 & \\
\hline Low maternal education $^{b}$ & 18.84 & & 21.09 & & 44.81 & \\
\hline Separated family & 21.21 & & 22.71 & & 17.44 & \\
\hline Family processes & Mean & $S D$ & Mean & $S D$ & Mean & $S D$ \\
\hline Positive interaction & 14.17 & 1.89 & 13.82 & 2.47 & 13.49 & 1.4 \\
\hline Hostile ineffective parenting & 7.74 & 1.99 & 9.46 & 2.88 & 11.34 & 1.74 \\
\hline Consistent parenting & 15.15 & 1.97 & 14.68 & 2.67 & 14.31 & 1.47 \\
\hline Family functioning & 7.45 & 2.92 & 8.15 & 3.77 & 8.86 & 2.14 \\
\hline
\end{tabular}

${ }^{a} 21$ years old or less at the birth of the first child.

${ }^{b}$ Mother did not graduate from high school. 
Table V. Predictors of High Physical Aggression Trajectory: Multivariate Logit Model

\begin{tabular}{|c|c|c|c|c|c|c|}
\hline & \multicolumn{3}{|c|}{ Model 1} & \multicolumn{3}{|c|}{ Model 2} \\
\hline & Estimate $(S D)$ & OR & $95 \% \mathrm{CI}^{a}$ & Estimate $(S D)$ & OR & $95 \% \mathrm{CI}^{a}$ \\
\hline Boys & $0.51(0.06)$ & $1.67^{* *}$ & $1.5-1.87$ & $0.44(0.07)$ & $1.56^{* *}$ & $1.37-1.77$ \\
\hline \multicolumn{7}{|l|}{ Family characteristics } \\
\hline Low income & $0.37(0.07)$ & $1.45^{* *}$ & $1.27-1.67$ & $0.48(0.08)$ & $1.61^{* *}$ & $1.36-1.90$ \\
\hline Early childbearing & $0.05(0.07)$ & 1.05 & $0.92-1.20$ & $0.01(0.08)$ & 1.01 & $0.86-1.18$ \\
\hline Low maternal education & $0.19(0.07)$ & $1.20^{*}$ & $1.05-1.38$ & $0.16(0.08)$ & $1.18^{*}$ & $1.00-1.38$ \\
\hline Separated family & $-0.04(0.10)$ & 0.96 & $0.79-1.17$ & $-0.09(0.11)$ & 0.91 & $0.73-1.15$ \\
\hline \multicolumn{7}{|l|}{ Family processes } \\
\hline Positive interaction & - & - & - & $-0.01(0.01)$ & 0.99 & $0.97-1.01$ \\
\hline Hostile ineffective parenting & - & - & - & $0.15(0.01)$ & $1.16^{* *}$ & $1.14-1.18$ \\
\hline Consistent parenting & - & - & - & $0.02(0.01)$ & 1.02 & $1.00-1.04$ \\
\hline Family functioning & - & - & - & $0.01(0.01)$ & 1.01 & $0.99-1.03$ \\
\hline
\end{tabular}

Note. $n=9635$ in model $1 ; n=7276$ in model 2.

${ }^{a} \mathrm{CI}$ indicates confidence interval.

${ }^{*} p<0.05$. $^{* *} p<0.001$.

This difference may be explained by the criteria used for model selection. While the two studies relied on the BIC for model selection, we also considered entropy, an index reflecting the degree to which the separation of the groups was adequate. Relying on both criteria, we selected the three-group model as the one best fitting the data. The moderate-desister group in our study appears to comprise two desister groups in the NICHD ECCRN results (the low and moderate decline groups). Similarly, the high group identified in the present sample appears to include the two highest trajectory groups in the NICHD ECCRN sample (the moderate and high groups).

Second, we identified a group of children representing $16.6 \%$ of the sample with high and stable levels of PA as compared to their peers. This developmental pattern was atypical in the sense that it was distinct from the general declining and lower levels of PA exhibited by the rest of the sample. Because most children reduced their use of PA and children in the high group did not, the magnitude of the difference between the former and the latter grew larger over the course of childhood. In preadolescence (age 11 years) children in the high PA group exhibited notably higher levels of PA as compared to their peers. For each age cohort the most physically aggressive children at cycle 1 tended to remain the most aggressive in the following three cycles. These findings are also in line with the NICHD-ECCRN (2004) results indicating that a proportion of children exhibit higher levels of PA during toddlerhood remain on relatively high trajectories throughout childhood. These two studies, in Canada and the US, replicate earlier analyses of PA trajectories during the elementary school years and high school in Canada, New Zealand and the US (Brame et al., 2001; Broidy et al., 2003; Nagin \& Tremblay, 1999), but show that the same phenomenon applies to the preschool years. Thus, toddlers who use PA more frequently are at relatively high risk of remaining on a high-level trajectory throughout the school years. This finding is in keeping with the severity hypothesis, postulating that the more extreme the antisocial behavior, the more stable it should be over time (Loeber, 1982). Thus, the trajectories identified in the school years (e.g., Brame et al., 2001; Broidy et al., 2003; Nagin \& Tremblay, 1999) appear to have their roots in the preschool years. Since assessments of PA began at 2 years, we were not able to detect its prior development. However, an observational study in day care centers (Restoin et al., 1985) and a study based on mother reports (Tremblay, 2004; Tremblay et al., 2004) both indicated a rapid increase in use of PA between the first and the third year after birth.

Third, contrary to other studies from the preschool to the elementary school years (Kingston \& Prior, 1995; Munson et al., 2001), we did not identify a group of children with increasing rates of aggression. This divergence appears to be due to two important methodological differences. First, previous studies included a wide range of externalizing behavior problems (such as opposition, and verbal aggression) in their definition of aggression whereas we focused on physical aggression. Second, previous studies often used a priori cut-off points to select groups that were labeled aggressive and not aggressive (see Nagin \& Tremblay, 1999). Given the declining trends in the development of PA, and the absence of a trajectory which shows increasing levels, it appears clear that from 2 years of age until pre-adolescence, children typically learn to suppress PA more than they learn to use it. Those 
who remain on a high-level trajectory appear to fail to learn to inhibit physically aggressive behaviors, and fail to learn alternative behavioral strategies (Tremblay, 2003). Studies of PA trajectories during adolescence have shown increases in frequency, especially by individuals on the chronic trajectory (Brame et al., 2001; Lacourse et al., 2002). However, these increases are followed by a rapid decline. With a large sample of juvenile delinquents followed up to old age, Sampson and Laub (2003) have also shown that there is a general tendency of decreasing antisocial behavior with age, including physical aggression. The results from these studies suggest that there are very few cases of children who are not physically aggressive during the preschool years and then become physically aggressive as they grow older.

A fourth aim of the study was to examine sex differences in PA. Our comparisons of boys and girls indicated that boys were 1.67 times more likely to follow the high and stable trajectory of PA. Thus, between 2 and 11 years of age, boys tended to be more physically aggressive than girls. Similar sex differences were found among participants in the NICHD ECCRN study: boys were more likely to follow a moderate (the second highest trajectory OR: 1.68 ) or a high (OR: 2.89) trajectory as compared to the (two) lowest trajectories. Together, these results suggest that the magnitude of the sex difference in PA is already quite large in toddlerhood—girls are already more likely to be on low desisting trajectories and boys more likely to be on high and more stable trajectories. The difference between males and females is also consistent with previous studies showing sex differences in social behavior, including PA during early childhood (Archer \& Côté, 2005; Kochanska, Murray, \& Harlan, 2000; Maccoby, 1998; Tremblay et al., 2004), and other studies showing that a much larger proportion of males follow a life-course persistent trajectory of antisocial behaviors from an early age (Moffitt et al., 2001).

A final aim of the study was to identify risk factors that distinguish children who follow atypically high PA trajectories from those who do not. We hypothesized that children with high levels of PA would have a more adverse family background and family environments as compared to all other children. Results from the logistic regression analyses showed that being male, being from a low income family and having a mother with a low level of education were all associated with the high and stable trajectory of PA. When adding family process variables to this model, the same variables remained significant and, in addition, hostile/ineffective parenting strongly predicted the high PA trajectory. Note that none of the risk factors interacted with the sex of the child, which indicates that the strength of the association between the risk factors and a high trajectory of PA did not vary by sex. This result is in line with a previous study indicating that most of the risk factors for persistent antisocial behaviors did not vary by sex (Moffitt et al., 2001).

Overall, the results of the present and of other studies (Nagin \& Tremblay, 2001; NICHD ECCRN, 2004; Tremblay et al., 2004) suggest that the failure to inhibit PA could be caused by factors similar to those proposed to be responsible for children's learning of PA. Indeed, family characteristics and family processes conceptualized as promoting aggression may interfere with the socialization of aggression (Tremblay, 2003). Thus, the family characteristics identified in the present study (low income, low maternal education) may reflect family environments in which children have difficulty learning to inhibit their use of physical aggression, as well as difficulty learning alternative strategies to solve problems. One possible mechanism by which this occurs is parenting: parents with high risk characteristics may use parenting practices that do not help children learn to inhibit PA and learn alternative strategies to achieve their aims (e.g., Patterson, 1982; Shaw \& Bell, 1993). However, we did not find parenting practices to explain the effects of family characteristics. We rather found that both had independent effects. Note that change in parenting was not assessed. Therefore, caution is required in interpreting the parenting effect: it may reflect the reciprocal influence between children and parents (Shaw \& Bell, 1993).

There are two other mechanisms by which family risks may interfere with children's socialization of aggression. First, children may have acquired, in utero and infancy, neurological deficits which limit their ability to learn to inhibit PA and use alternative strategies (Moffitt, 2003; Raine, 2002; Tremblay et al., 2004). Secondly, genetic factors may also be involved. Parents may share with their children genetic characteristics which do not facilitate learning of emotional regulation and inhibition of overt aggression. Genetically informative studies such as twin, adoption, and molecular genetic studies are needed to test the contribution of genetic factors and the likely gene-environment interactions and geneenvironment correlations (e.g., Arseneault et al., 2003; Caspi et al., 2002; Dionne et al., 2003; Weaver et al, 2004)

There are limitations to this study. First, the developmental patterns that we observed for PA do not necessarily generalize to other types of aggression. For instance, levels of indirect aggression have been shown to increase during the course of childhood (Côté et al., in press; Vaillancourt, 2005). Second, the use of an accelerated longitudinal design to study the developmental trajectories of PA in a large representative sample $(n=10,658)$ 
is an important methodological innovation. However, the findings still need to be replicated with the youngest cohort once they have been assessed up to 11 years of age. Third, as the results indicated, an initial assessment at 2 years of age was too late to describe the "onset" of PA since children tended to exhibit their highest levels of these behaviors at the time of their initial assessment. A further limit is the reliance on mother ratings for the assessment of PA in the final model. The time line covered by the present study (toddlerhood to pre-adolescence) in combination with the type of sample (large and representative) make it difficult to rely on other sources of information than the parent. But, similar developmental patterns were observed during early childhood from observational data (Restoin et al., 1985). Still, the results need to be replicated with studies providing data from other informants that can assess children from infancy to adolescence (e.g., observers, day care educators and teachers). Finally, the items we selected to describe physical aggression from 2 to 11 years of age were originally conceived for studies of school age children (Achenbach \& Edelbrock, 1983; Cairns et al., 1989; Rutter, Tizard, \& Whitmore, 1970; Tremblay et al., 1991). It will be important, in future studies, to measure a wider variety of physically aggressive behaviors, as well as different forms of aggression (such as reactive and proactive aggression: Dodge, Lochman, Harnish, Bates, \& Pettit, 1997; Tremblay, 2000; Vitaro, Gendreau, Tremblay, \& Oligny, 1998) to examine their developmental trajectories.

Understanding the typical and atypical development of PA from its origins should assist in planning strategies to support children's learning of alternatives to physical aggression. It appears clear from our results that the majority of preschool children are learning to inhibit PA but that a minority are not. As they grow older and physically stronger, children in that minority may become important threats to their environment. The preschool years appear to be an appropriate moment to start preventing the development of chronic physical aggression.

\section{ACKNOWLEDGMENTS}

This research was supported by research grants from Quebec's FQRSC and CIQSS, from Canada's CIHR and SSHRC, from the Canadian Institute for Advanced Research, the Molson foundation, St-Justine Hospital's Research Center and the University of Montréal. We thank Franck Larouche (Statistics Canada) for his sustained commitment to assist us in managing the data and Danielle Forest (University of Montréal) for her precious help with statistical analyses.

\section{REFERENCES}

Achenbach, T. M., \& Edelbrock, C. (1983). Manual for the child behavior checklist and revised child behavior profile. Burlington, VT: University of Vermont, Department of Psychiatry.

Archer, J., \& Côté, S. (2005). The development of sex differences in aggressive behavior: An evolutionary perspective. In R. E. Tremblay, W. W. Hartup \& J. Archer (Eds.), Developmental origins of aggression (pp. 425-443). New York: Guilford.

Arseneault, L., Moffit, T. E., Caspi, A., Taylor, A., Rijsdijk, F. V., Jaffee, S. R., et al. (2003). Strong genetic effects on cross-situational antisocial behaviour among 5-year-old children according to mothers, teachers, examiner-observers, and twins' self-reports. Journal of Child Psychology and Psychiatry, 44, 832-848.

Bandura, A. (1973). Aggression: A social learning analysis. Englewood Cliffs, NJ: Prentice-Hall.

Boulerice, B. (2001). General Nonlinear Mixtures of Curves (MOC). Statistical software program. http://lib.stat.cmu.edu/R/CRAN/.

Boyle, M. H., Offord, D. R., Hofmann, H. G., Catlin, G. P., Byles, G. A., Cadman, D. T., et al. (1987). Ontario child care study: I Methodology. Archives of General Psychiatry, 44, 826-831.

Brame, B., Nagin, D. S., \& Tremblay, R. E. (2001). Developmental trajectories of physical aggression from school entry to late adolescence. The Journal of Child Psychology and Psychiatry, 58, 389-394.

Broidy, L. M., Nagin, D. S., Tremblay, R. E., Brame, B., Dodge, K., Fergusson, D., et al. (2003). Developmental trajectories of childhood disruptive behaviors and adolescent delinquency: A six site, cross national study. Developmental Psychology, 39, 222-245.

Cairns, R. B. (1979). The analysis of social interactions: Method, results and illustrations. Hillsdale, NJ: Lawrence Erlbaum.

Cairns, R. B., Cairns, B. D., Neckerman, H. J., Ferguson, L. L., \& Gariépy, J. L. (1989). Growth and aggression: 1. Childhood to early adolescence. Developmental Psychology, 25, 320-330.

Caspi, A., McClay, J., Moffitt, T., Mill, J., Martin, J., Craig, I. W., et al. (2002). Role of genotype in the cycle of violence in maltreated children. Science, 297, 851-854.

Côté, S. M., Vaillancourt, T., Barker, T., Nagin, D., \& Tremblay, R. E. (in press). Predictors of Continutity and Change in the Joint Development of Physical and Indirect Aggression. Development and Psychopathology,

Crick, N. R., Ostrov, J. M., Appleyard, K., Jansen, E. A., \& Casas, J. F. (2004). Relational aggression in early childhood: "You can't come to my birthday party unless..." In M. Putallaz \& K. L. Bierman (Eds.), Aggression, antisocial behavior, and violence among girls: A developmental perspective (pp. 71-89). New York: Guilford Press.

Darwin, C. (1872). The expression of the emotions in man and animals. London: John Murray, reprinted by Gryphon Editions 1989.

Dionne, G., Tremblay, R. E., Boivin, M., Laplante, D., \& Pérusse, D. (2003). Physical aggression and expressive vocabulary in 19 monthold twins. Developmental Psychology, 39, 261-273.

Dodge, K., Lochman, J. E., Harnish, J. D., Bates, J. E., \& Pettit, G. S. (1997). Reactive and proactive aggression in school children and psychiatrically impaired chronically assaultive youth. Journal of Abnormal Psychology, 106, 37-51.

Goodenough, F. L. (1931). Anger in young children. Westport, CT: Greenwood Press.

Hay, D. F., Castle, J., \& Davies, L. (2000). Toddlers' use of force against familiar peers: A precursor of serious aggression? Child Development, 71, 457-467.

Human Resources Development Canada and Statistics Canada. (1996). Growing up in Canada: National Longitudinal Survey of Children and Youth. Ottawa: Statistics Canada.

Jaffee, S., Caspi, A., Moffitt, T. E., Belsky, J., \& Silva, P. (2001). Why are children born to teen mothers at risk for adverse outcomes in young 
adulthood? Results from a 20-year longitudinal study. Development and Psychopathology, 13, 377-397.

Johnson, J. G., Cohen, P., Smailes, E. M., Kasen, S., \& Brook, J. S. (2002). Television viewing and aggressive behavior during adolescence and adulthood. Science, 295, 2468-2471.

Jones, B. L., Nagin, D. S., \& Roeder, K. (2001). A SAS procedure based on mixture models for estimating developmental trajectories. Sociological Methods and Research, 29, 374-393.

Keenan, K., \& Shaw, D. S. (1994). The development of aggression in toddlers: A study of low-income families. Journal of Abnormal Child Psychology, 22, 53-77.

Keenan, K., \& Shaw, D. (1997). Developmental and social influences on young girls' early problem behaviors. Psychological Bulletin, 121, 95-113.

Keenan, K., \& Wakschlag, L. S. (2000). More than the terrible twos: The nature and severity of behavior problems in clinic-referred preschool children. Journal of Abnormal Child Psychology, 28, 33-46.

Kingston, L., \& Prior, M. (1995). The development of patterns of stable, transient, and school-age onset aggressive behavior in young children. Journal of the American Academy of Child and Adolescent Psychiatry, 34, 348-358.

Kochanska, G., Murray, K. T., \& Harlan, E. T. (2000). Effortful control in early childhood: Continuity and change, antecedents, and implications for social development. Developmental Psychology, 36, 220-232.

Krug, E. G., Dahlberg, L. L., Mercy, J. A., Zwi, A. B., \& Lozano, R. E. (2002). World report on violence and health. World Health Organization. Retrieved, 2002, from the World Wide Web: www.who. int/violence_injury_prevention/violence/world_report/wrvh1/en.

Lacourse, E., Côté, S., Nagin, D. S., Vitaro, F., Brendgen, M., \& Tremblay, R. E. (2002). A longitudinal-experimental approach to testing theories of antisocial behavior development. Development and Psychopathology, 14, 909-924.

Loeber, R. (1982). The stability of antisocial and delinquent child behavior: A review. Child Development, 53, 1431-1446.

Loeber, R., \& Stouthamer-Loeber, M. (1998). Development of juvenile aggression and violence. Some common misconceptions and controversies. American Psychologist, 53, 242-259.

Lorenz, K. (1966). On aggression. New York: Harcourt, Brace and World.

Maccoby, E. (1998). The two sexes. Cambridge: Harvard University Press.

McCord, J., Widom Spatz, C., \& Crowell, N. (2001). Juvenile crime, juvenile justice. Washington, DC: National Academy Press.

Moffitt, T. E., Caspi, A., Rutter, M., \& Silva, P. (2001). Sex differences in antisocial behavior. Cambridge, UK: Cambridge University Press.

Moffitt, T. E. (2003). Life-course-persistent and adolescence-limited antisocial behavior: A 10-year research review and a research agenda. In B. B. Lahey, T. E. Moffitt, \& A. Caspi (Eds.), Causes of conduct disorder and juvenile delinquency (pp. 49-75). New York: Guilford Press.

Munson, J. A., McMahon, R. J., \& Spieker, S. J. (2001). Structure and variability in the developmental trajectory of children's externalizing problems: Impact of infant attachment, maternal depressive symptomatology, and child sex. Development and Psychopathology, 13, 277-296.

Nagin, D. (1999). Analyzing developmental trajectories: A semiparametric, group-based approach. Psychological Methods, 4, 139177.

Nagin, D. S. (2005). Group-based modeling of development. Cambridge, MA: Harvard University Press.

Nagin, D., \& Tremblay, R. E. (1999). Trajectories of boys' physical aggression, opposition, and hyperactivity on the path to physically violent and non violent juvenile delinquency. Child Development, 70, 1181-1196.

Nagin, D., \& Tremblay, R. E. (2001). Parental and early childhood predictors of persistent physical aggression in boys from kindergarten to high school. Archives of General Psychiatry, 58, 389-394.
NICHD Early Child Care Research Network (2004). Trajectories of physical aggression from toddlerhood to middle childhood. Monographs of the Society for Research in Child Development. Serial No. 278, Vol. 69, 4.

National Longitudinal Survey of Children and Youth (NLSCY) (19941995). User guide. Special Surveys Division, Statistics Canada. http://www.statcan.ca/english/Dli/Data/Ftp/nlscy.htm

Patterson, G. R. (1982). Coercive family process. Eugene, OR: Castalia.

Patterson, G. R., Reid, J. B., \& Dishion, T. J. (1992). A social interactional approach: Vol 4. Antisocial boys. Eugene, OR: Castalia.

Raine, A. (2002). Annotation: The role of prefrontal deficits, low autonomic arousal, and early health factors in the development of antisocial and aggressive behavior in children. Journal of Child Psychology and Psychiatry, 43, 417-434.

Reiss, A. J., \& Roth, J. A. (1993). Understanding and preventing violence. Washington, DC: National Academy Press.

Restoin, A., Montagner, H., Rodriguez, D., Girardot, J. J., Laurent, D. Kontar, F., Ullmann, V., Casagrande, C., \& Talpain, B. (1985). Chronologie des comportements de communication et profils de comportement chez le jeune enfant. In R. E. Tremblay, M. A. Provost, \& F. F. Strayer (Eds.), Ethologie et développement de l'enfant (pp. 93-130). Paris: Editions Stock/Laurence Pernoud.

Rutter, M., Tizard, J., \& Whitmore, K. (1970). Education, health and behavior. New York: John Wiley and Sons.

Sampson, R. J., \& Laub, J. H. (2003). Life-course desisters? Trajectories of crime among delinquent boys followed to age 70. Criminology, $41,301-339$.

Schwarz, G. (1978). Estimating the dimension of a model. Annals of Statistics, 6, 461-464.

Shaw, D. S., \& Bell, R. Q. (1993). Developmental theories of parental contributors to antisocial behavior. Journal of Abnormal Child Psychology, 21, 493-518.

Shaw, D., Gilliom, M., Ingoldsby, E. v, \& Nagin, D. S. (2003) Trajectories leading to school-age conduct problems. Developmental Psychology, 39, 189-200.

Statistics Canada. (1995). Overview of survey instruments for 1994-95 data collection, cycle 1. Ottawa: Statistics Canada.

Straus, M. A., \& Gelles, R. J. (1990). Physical violence in American families: Risk factors and adaptations to violence in 8,145 families. New Brunswick, NJ: Transaction Publishers.

Thornberry, T. (1998). Membership in youth gangs and involvement in serious and violent offending. In R. Loeber \& D. P. Farrington (Eds.), Serious and violent juvenile offenders: Risk factors and successful interventions (pp. 147-166). Thousand Oaks, CA: Sage Publications.

Tremblay, R. E. (2000). The development of aggressive behaviour during childhood: What have we learned in the past century? International Journal of Behavioral development, 24, 129-141.

Tremblay, R. E. (2003). Why socialization fails?: The case of chronic physical aggression. In B. B. Lahey, T. E. Moffitt, \& A. Caspi (Eds.), Causes of conduct disorder and juvenile delinquency (pp. 182-224). New York: Guilford Publications.

Tremblay, R. E. (2004). The development of human physical aggression: How important is early childhood? In L. A. \& Leavitt, D. M. B. Hall (Eds.), Social and moral development: Emerging evidence on the toddler years (pp. 221-238). New Brunswick, NJ: Johnson and Johnson Pediatric Institute.

Tremblay, R. E., \& Nagin, D. S. (2005). The developmental origins of physical aggression in humans. In R. E. Tremblay, W. H. Hartup, \& J. Archer (Eds.), Developmental origins of aggression. (pp. 83106) New York: Guilford Press.

Tremblay, R. E., Boulerice, B., Harden, P. W., McDuff, P., Pérusse, D., Pihl, R. O., et al. (1996). Do children in Canada become more aggressive as they approach adolescence? In Human Resources Development Canada \& Statistics Canada (Eds.), Growing up in Canada: National Longitudinal Survey of Children and Youth (pp. 127-137). Ottawa: Statistics Canada.

Tremblay, R. E., Japel, C., Pérusse, D., McDuff, P., Boivin, M., Zoccolillo, M., et al. (1999). The search for the age of «onset》 
of physical aggression: Rousseau and Bandura revisited. Criminal Behavior and Mental Health, 9, 8-23.

Tremblay, R. E., Loeber, R., Gagnon, C., Charlebois, P., Larivée, S., \& LeBlanc, M. (1991). Disruptive boys with stable and unstable high fighting behavior patterns during junior elementary school. Journal of Abnormal Child Psychology, 19, 285-300.

Tremblay, R. E., Nagin, D. S., Séguin, J. R., Zoccolillo, M., Zelazo, P. D., Boivin, M., et al. (2004). Physical aggression during early childhood: Trajectories and predictors. Pediatrics, 114, $43-50$.

Vaillancourt, T. (2005). Indirect aggression among humans: Social construct or evolutionary adaptation? In R. E. Tremblay, W. W. Hartup
\& J. Archer (Eds.), Developmental origins of aggression (pp. 158177). New York: Guilford.

Vitaro, F., Gendreau, P. L., Tremblay, R. E., \& Oligny, P. (1998). Reactive and proactive aggression differentially predict later conduct problems. Journal of Child Psychology and Psychiatry, 39, $1-9$.

Weaver, I. C. G., Cervoni, N., Champagne, F. A., D’Alessio, A. C., Sharma, S., Seckl, J. R., et al. (2004). Epigenetic programming by maternal behavior. Nature Neuroscience, 7, 847-854.

Welsh, M., Parke, R. D., Widaman, K., \& O'Neil, R. (2001). Linkages between children's social and academic competence: A longitudinal analysis. Journal of School Psychology, 39, 463-481. 